This item was submitted to Loughborough's Research Repository by the author.

Items in Figshare are protected by copyright, with all rights reserved, unless otherwise indicated.

\title{
Chronic ingestion of a low dose of caffeine induces tolerance to the performance benefits of caffeine
}

PLEASE CITE THE PUBLISHED VERSION

http://dx.doi.org/10.1080/02640414.2016.1241421

\section{PUBLISHER}

(C) Taylor and Francis

\section{VERSION}

AM (Accepted Manuscript)

\section{PUBLISHER STATEMENT}

This work is made available according to the conditions of the Creative Commons Attribution-NonCommercialNoDerivatives 4.0 International (CC BY-NC-ND 4.0) licence. Full details of this licence are available at: https://creativecommons.org/licenses/by-nc-nd/4.0/

\section{LICENCE}

CC BY-NC-ND 4.0

\section{REPOSITORY RECORD}

Beaumont, Ross, Philip Cordery, Mark P. Funnell, Stephen A. Mears, Lewis J. James, and Phillip Watson. 2019. "Chronic Ingestion of a Low Dose of Caffeine Induces Tolerance to the Performance Benefits of Caffeine". figshare. https://hdl.handle.net/2134/23508. 
Full title: Chronic ingestion of a low-dose of caffeine induces tolerance to the performance benefits of caffeine

Running title: Caffeine tolerance and endurance performance

Ross Beaumont ${ }^{1}$, Phillip Cordery ${ }^{1}$, Mark Funnell ${ }^{1}$, Stephen Mears ${ }^{1}$, Lewis James ${ }^{1}$ and Phillip Watson ${ }^{2}$

${ }^{1}$ School of Sport, Exercise and Health Sciences, Loughborough University, Leicestershire, LE11 3TU, UK.

${ }^{2}$ Department of Human Physiology and Sports Medicine, Vrije Universiteit Brussel, Brussels B-1050, Belgium.

Correspondence: Ross Beaumont,

School of Sport, Exercise and Health Sciences, Loughborough University, Leicestershire, LE11 3TU, UK

Email: $\quad$ r.e.beaumont@lboro.ac.uk

Key words: Fatigue, habituation, exercise metabolism, stimulants, supplements 


\section{Abstract}

This study examined effects of four weeks of caffeine supplementation on endurance performance. Eighteen low-habitual caffeine consumers (<75 mg.day ${ }^{-1}$ ) were randomly assigned to ingest caffeine $\left(1.5-3.0 \mathrm{mg} \cdot \mathrm{kg}^{-1} \mathrm{day}^{-1}\right.$; titrated) or placebo for 28 days. Groups were matched for age, body mass, $\dot{V}_{2 \text { peak }}$ and $W_{\max }(P>0.05)$. Before supplementation, all participants completed one $\dot{\mathrm{V}}_{2 \text { peak }}$ test, one practice trial and two experimental trials (acute $3 \mathrm{mg} \cdot \mathrm{kg}^{-1}$ caffeine [precaf] and placebo [testpla]). During the supplementation period a second $\dot{\mathrm{V}}_{2 \text { peak }}$ test was completed on day 21 before a final, acute $3 \mathrm{mg} \cdot \mathrm{kg}^{-1}$ caffeine trial (postcaf) on day 29. Trials consisted of 60 min cycle exercise at $60 \% \mathrm{~V}_{2}$ peak followed by a 30 min performance task. All participants produced more external work during the precaf trial than testpla, with increases in the caffeine ( $383.3 \pm 75 \mathrm{~kJ}$ vs. $344.9 \pm 80.3 \mathrm{~kJ}$; Cohen's $d$ effect size [ES] $=0.49 ; P=0.001)$ and placebo $(354.5 \pm 55.2 \mathrm{~kJ}$ vs. $333.1 \pm 56.4 \mathrm{~kJ} ; \mathrm{ES}=0.38$; $P=0.004)$ supplementation group, respectively. This performance benefit was no longer apparent after four weeks of caffeine supplementation (precaf: $383.3 \pm 75.0$ kJ vs. postcaf: $358.0 \pm 89.8 \mathrm{~kJ}$; $E S=0.31 ; P=0.025$ ), but was retained in the placebo group (precaf: $354.5 \pm 55.2 \mathrm{~kJ}$ vs. postcaf: $351.8 \pm 49.4 \mathrm{~kJ}$; ES=0.05; $P>0.05$ ). Circulating caffeine, hormonal concentrations and substrate oxidation did not differ between groups (all $P>0.05$ ). Chronic ingestion of a low dose of caffeine develops tolerance in low-caffeine consumers. Therefore, individuals with low-habitual intakes should refrain from chronic caffeine supplementation to maximise performance benefits from acute caffeine ingestion.

Key words: Fatigue, habituation, exercise metabolism, stimulants, supplements 
1 Introduction

2 Acute caffeine (1,3,7-trimethylxanthine) supplementation approximately one hour

3 before exercise improves endurance performance in laboratory-based studies (Burke,

4 2008). The same occurs in the field (Berglund \& Hemmingsson, 1982), leading to its

5 widespread use by athletes during competition (Desbrow \& Leveritt, 2006). To

6 determine optimum conditions by which caffeine improves performance, factors such

7 as dose (Desbrow et al., 2012), source (Hodgson, Randell, \& Jeukendrup, 2013),

8 and the timing of intake (Cox et al., 2002) have been investigated. However,

9 habituation to chronic caffeine intake has received less attention (Bell \& McLellan,

10 2002). This is important from a practical standpoint given the high prevalence of daily

11 caffeine intake in the general population (Fitt, Pell, \& Cole, 2013) and by athletes

12 during competition (Desbrow \& Leveritt, 2006).

13 Caffeine probably improves exercise performance through its role as a non-selective

14 adenosine receptor antagonist (Fredholm, Bättig, Holmén, Nehlig, \& Zvartau, 1999).

15 A prominent role for the adenosine $A_{1}$ receptor in mediating the acute performance

16 enhancing effects of caffeine has been demonstrated (Snyder, Katims, Annau, Bruns,

17 \& Daly, 1981). However, more recent studies with adenosine $A_{2 A}$ receptor knockout

18 mice confirmed that central blockade of this adenosine receptor isoform is largely

19 responsible for the performance enhancing properties of the drug (El Yacoubi et al.,

20 2000). Chronic caffeine intake influences the concentration of $A_{1}$ and $A_{2 A}$ receptors in

21 several brain regions (Svenningsson, Nomikos, \& Fredholm, 1999; Johansson et al., 22 1993). This includes $A_{2 A}$ expression in the striatum (Svenningsson et al., 1999), a 23 sub-cortical region essential for coordinating voluntary actions (Tepper, Wilson, \& 24 Koós, 2008). Therefore it is possible that habituation influences performance benefits 25 typical of acute caffeine supplementation. Data from animal studies support this 
26 hypothesis, as chronic exposure to caffeine in the drinking water of rats resulted in

27 tolerance to the performance benefit of a subsequent acute caffeine dose (Karcz-

28 Kubicha et al., 2003). Although these findings have been confirmed in other animal

29 models (Quarta et al., 2004), the doses administered have been large (i.e. 130

$30 \mathrm{mg} \cdot \mathrm{kg} \cdot \mathrm{day}^{-1}$ ) and much greater than those typically consumed by the general

31 population (Fitt et al., 2013). Whether the same tolerance develops after habituation

32 to doses typically consumed by the general population is not clear.

33 The magnitude of performance benefit after an acute $5 \mathrm{mg} \cdot \mathrm{kg}^{-1}$ caffeine dose was

34 less pronounced in individuals already habituated to caffeine $\left(>300 \mathrm{mg} \cdot \mathrm{day}^{-1}\right)$ than

35 their caffeine-naive counterparts (Bell \& McLellan, 2002). Similar metabolic

36 responses have occurred after an acute caffeine dose in comparisons of low-and

37 high-habitual caffeine users (Bangsbo, Jacobsen, Nordberg, Christensen, \& Graham,

38 1992). However, sub-chronic intake (5 days) both of low ( $3 \mathrm{mg} \cdot \mathrm{kg}^{-1}$ ) and moderate

$39\left(6 \mathrm{mg} \cdot \mathrm{kg}^{-1}\right)$ caffeine doses did not influence thermoregulatory or cardiovascular

40 responses during exercise in the heat (Roti et al., 2006). Furthermore, time-trial

41 performance was similar when individuals received an acute $3 \mathrm{mg} \cdot \mathrm{kg}^{-1}$ caffeine dose

42 subsequent to either a four-day habituation (3 $\mathrm{mg} \cdot \mathrm{kg}^{-1} \mathrm{day}^{-1}$ ) or withdrawal period

43 (Irwin et al., 2011). These data suggest that a greater duration of supplementation is

44 required before the performance benefit of an acute caffeine dose becomes

45 compromised. To date, no study has systematically evaluated a prolonged period of

46 controlled caffeine intake and its influence on endurance performance. Hence, the

47 aim of this study was to examine the effect of a four-week period of controlled

48 caffeine supplementation on endurance performance. 
Methods

51 Participants

52 Eighteen healthy, recreationally active men (age: $21.2 \pm 1.8$ y; body mass: $74.1 \pm 8.6$

$53 \mathrm{~kg}$; stature: $1.75 \pm 0.06 \mathrm{~m}$; $\mathrm{V}_{2 \text { peak: }}: 51.4 \pm 8.7 \mathrm{ml} \cdot \mathrm{kg}^{-1} \cdot \mathrm{min}^{-1} ; W_{\max }: 289 \pm 46 \mathrm{~W}$ ) were

54 recruited and completed this study. All participants were free from chronic disease 55 and deemed eligible to participate after the completion of a health screen 56 questionnaire. Habitual caffeine intake was assessed using a modified version of a 57 semi-quantitative food-frequency questionnaire (Addicot, Yang, Peiffer, \& Laurienti, 58 2008) to ensure intake did not exceed $75 \mathrm{mg} \cdot$ day $^{-1}$. This cut-off point was chosen as 59 it equates to approximately one cup of caffeinated instant coffee (Fitt et al., 2013) 60 and is similar to what has been used previously (Bell \& McLellan, 2002). The study 61 was approved by the Ethics Approvals (Human Participants) Sub-Committee at 62 Loughborough University, UK.

64 Experimental Design

65 The experimental design is illustrated in Fig 1. All participants attended the 66 laboratory on six occasions. During the initial visit each participant undertook an 67 incremental exercise test to volitional exhaustion on an electronically braked cycle 68 ergometer (Lode Corival, Groningen, the Netherlands) to determine $\dot{\mathrm{VO}}_{2 \text { peak }}$ and 69 peak power output at $\dot{V}_{2 \text { peak }}\left(W_{\max }\right)$ After this visit, each participant completed one 70 practice trial. This was undertaken to ensure that all participants were accustomed to 71 procedures, to minimise order effects from learning or anxiety and ensure attainment 72 of a maximal effort during the performance task. 
73 After these initial tests, each participant completed one acute caffeine trial (precaf)

74 and one placebo trial (testpla), each separated by 5-7 days. Thereafter, participants 75 were randomly assigned to ingest daily doses of caffeine (BDH Ltd, Poole, UK) or starch (250 mg: BHD Ltd, Poole, UK) for 28 days. Both supplementation groups 77 were matched for age, stature, body mass, $\dot{V}_{2 \text { peak }}$ and $W_{\max }(P>0.05)$. During the 78 first seven days of supplementation, the caffeine group ingested half of the 79 prescribed caffeine dose $\left(1.5 \mathrm{mg} \cdot \mathrm{kg}^{-1}\right)$ in their morning capsule $(7-9 \mathrm{am})$ followed by a placebo capsule (250 mg starch) in the afternoon (1-3 pm). From days 8 to 28 , the

81 caffeine group received the full $3 \mathrm{mg} \cdot \mathrm{kg}^{-1}$ dose, equally divided between the morning 82 and afternoon capsules. This titrated approach minimised negative influences of 83 caffeine on daily activities in caffeine-naive individuals (e.g. jitteriness, disturbed sleep etc). The placebo group followed the same pattern of intake, but received starch $(250 \mathrm{mg})$ in both capsules. All participants were instructed to ingest the capsules at the same time of day throughout the supplementation period and 87 compliance was verified by telephone contact, email and in person. Both the placebo and caffeine capsules were visually identical and blinded by an external party not involved in any stage of data collection. A second incremental exercise test was completed on the morning of day 21 , before the ingestion of any capsules. This followed the same procedure as the initial visit and was undertaken to account for any changes in $\dot{\mathrm{V}}_{2 \text { peak }}$ before the final single-blind acute $3 \mathrm{mg} \cdot \mathrm{kg}^{-1}$ caffeine trial on day 29 (postcaf).

94 The order of the testpla and precaf trials and assignment to either supplementation 95 group was via a double-blind, randomised design. Participants were instructed to 96 record their dietary intake and physical activity patterns in the $24 \mathrm{hr}$ before their first experimental trial and replicate this on the day before each subsequent experimental 
98

trial. No strenuous exercise, alcohol, or caffeine ingestion was permitted during the $24 \mathrm{hr}$ before any laboratory visit. However, the caffeine provided in the capsules was permitted during the $24 \mathrm{hr}$ before the postcaf trial (caffeine group). No additional dietary caffeine was permitted during the supplementation period in both groups and participants were provided with a list of commonly consumed caffeinated foods and beverage to help achieve this. Participants were also instructed to maintain their usual dietary and exercise patterns throughout the supplementation period. Compliance to these measures was verified at the start of each visit, before any data collection. Finally, all trials were performed at the same time of day to minimise circadian-type variations in performance.

\section{Experimental trials}

Participants arrived at the laboratory after an overnight fast (8-10 hr) with the exception of ingesting $500 \mathrm{~mL}$ of plain water approximately 90 min before. Upon arrival, post-void nude body mass was recorded to the nearest $10 \mathrm{~g}$ (Adam AFW120K, Milton Keynes, UK) and a heart rate telemetry band (Polar Beat, Kempele, Finland) positioned. After 10 min of supine rest, a $21 \mathrm{~g}$ cannula was inserted into an antecubital vein to allow repeated blood sampling. The cannula was flushed with a small volume of saline after each sample to ensure patency. A baseline blood sample $(7 \mathrm{~mL})$ was collected before participants ingested either $3 \mathrm{mg} \cdot \mathrm{kg}^{-1}$ of anhydrous caffeine (precaf and postcaf) or $250 \mathrm{mg}$ of starch (testpla). After $60 \mathrm{~min}$ rest, a second $7 \mathrm{~mL}$ venous blood sample was drawn before participants cycled for 60 min at an intensity equivalent to $60 \% \mathrm{~V}_{2 \text { peak }}$. During this period heart rate and rating of perceived exertion (RPE) were recorded every 5 and 10 min, respectively 
122 (Borg, 1982). One-minute expired air samples were collected into Douglas bags

123 every 15 min to determine the rates of fat and carbohydrate oxidation (Peronnet \&

124 Massicotte, 1991). Oxygen and carbon dioxide concentrations in each bag were

125 determined with a paramagnetic analyser (Servomex 1400, Sussex, UK) calibrated

126 against gases of known concentration on the morning of each trial. Total volume was

127 quantified (Harvard Dry Gas Meter, Harvard Apparatus, USA) and gas values were 128 expressed as STPD. After each sample was collected, participants were provided 129 with $100 \mathrm{~mL}$ of plain water. A third $7 \mathrm{~mL}$ blood sample was collected immediately 130 after the fixed-intensity exercise.

131 After this, there was a 2-3 min delay while the ergometer was set for the 132 performance task. Performance was assessed as the maximum amount of external 133 work $(\mathrm{kJ})$ that could be completed in $30 \mathrm{~min}$. This method is consistent with previous 134 studies (Jenkins, Trilk, Singhal, O'Connor, \& Cureton, 2008) and reflected the high 135 ecological validity associated with similar cycle-based performance tests 136 (Jeukendrup, Saris, Brouns, \& Kester, 1996). Participants began exercise at 75\% $137 \dot{\mathrm{V}} \mathrm{O}_{2 \text { peak, }}$, but were free to adjust the intensity of exercise from the outset. During the 138 performance task participants were instructed to maintain a constant cadence. No 139 verbal encouragement was given during this period and contact was limited to the 140 recording of the physiological and perceptual variables. Heart rate was recorded 141 every 5 min and RPE at 10 and $20 \mathrm{~min}$, respectively. A final $7 \mathrm{~mL}$ blood sample was 142 collected at completion of exercise, after which the cannula was removed. 
147 Blood samples $(7 \mathrm{~mL})$ were collected directly into dry syringes. A small sample $(2 \mathrm{~mL})$

148 was dispensed into tubes containing $\mathrm{K}_{2}$ EDTA. Duplicate $100 \mu \mathrm{L}$ sub-samples were 149 rapidly deproteinised in $1 \mathrm{~mL}$ of ice-cold $0.3 \mathrm{M}$ perchloric acid. These were 150 centrifuged and the resulting supernatant was used to determine blood glucose 151 concentrations (GOD-PAP, Randox Ltd, UK). Haemoglobin was measured in 152 duplicate (cyanmethemoglobin method) and haematocrit in triplicate 153 (microcentrifugation). These values were used to estimate percentage changes in 154 blood and plasma volumes relative to the resting sample (Dill \& Costill, 1974). The 155 remaining blood $(5 \mathrm{~mL})$ was dispended into tubes containing clotting activator and 156 left at room temperature for at least $60 \mathrm{~min}$ before centrifugation at $3000 \mathrm{rpm}$ for 10 $157 \min$ at $4^{\circ} \mathrm{C}$. The supernatant was stored at $-21^{\circ} \mathrm{C}$ for the determination of serum 158 prolactin and cortisol in duplicate via ELISA (DRG diagnostics, Germany) and serum 159 caffeine in duplicate with reverse-phase HPLC as previously described (Holland, 160 Godfredsen, Page, \& Connor, 1998). The intra-assay coefficient of variation (CV) for 161 serum prolactin, cortisol and caffeine was $4.9 \%, 5.3 \%$ and $2.9 \%$, respectively.

163 Statistical analysis

164 All data were analysed using IBM SPSS statistics version 21.0. Normality was 165 assessed with the Shapiro Wilk test. Between-group comparisons of self-reported 166 habitual caffeine intake, stature, body mass, age, $\dot{V} O_{2 p e a k}$ and $W_{\max }$ were determined 167 with $t$-tests for independent samples. Repeated measurements of body mass, $168 \dot{\mathrm{V}}_{\text {2peak }}$ and $W_{\max }$ were analysed using a two-way (group $\mathrm{x}$ time) mixed-design 169 factorial ANOVA. Exercise performance and fasting plasma glucose were analysed 
170 using a two-way (group $\mathrm{x}$ trial) mixed-design factorial ANOVA. Variables measured

171 throughout each trial were analysed using a three-way (group $x$ trial $x$ time) mixed-

172 design factorial ANOVA. Where a main effect or interaction occurred, Bonferroni

173 adjusted paired $t$-tests for normally distributed data or Wilcoxon Signed Rank tests

174 for non-normally distributed data were used. Between-group comparisons during the

175 testpla, precaf and postcaf trials were determined with $t$-tests for independent 176 samples. In addition to null-hypothesis testing, magnitude-based inferences were

177 made to examine whether the observed differences in total external work produced 178 were meaningful (Hopkins, 2000). The magnitude of the smallest worthwhile change 179 in performance was set at $3 \%(\sim 12 \mathrm{~kJ})$, based on the findings of Jenkins et al. (2008) 180 using habituated, recreationally active participants. Cohen's $d$ effect size (ES) 181 examined the magnitude of individual differences in total external work produced 182 ([Mean 1 - Mean 2]/pooled SD) and were interpreted as trivial (0-0.19), small (0.2183 0.49), medium (0.5-0.79) or large (>0.8) as previously described (Cohen, 1992). 184 Data are presented as means \pm SD unless otherwise stated. Statistical significance 185 was accepted at $P<0.05$.

187 Results

188 Baseline measures

189 Self-reported habitual caffeine intake was similar between groups (placebo: $66 \pm 6$ $190 \mathrm{mg} \cdot \mathrm{day}^{-1}$ vs. caffeine: $60 \pm 8 \mathrm{mg} \cdot \mathrm{day}^{-1} ; P=0.076$ ) There were no between-group 191 differences for baseline measures of age (placebo: $21.3 \pm 2.2 \mathrm{y}$; caffeine: $21.0 \pm 1.5$ $192 \mathrm{y} ; P=0.710$ ), stature (placebo: $1.75 \pm 0.06 \mathrm{~m}$; caffeine: $1.76 \pm 0.08 \mathrm{~m} ; P=0.781$ ), 193 body mass (placebo: $73.3 \pm 7.4 \mathrm{~kg}$; caffeine: $74.8 \pm 10.1 \mathrm{~kg} ; P=0.708$ ), $\dot{\mathrm{V}}_{2 \text { peak }}$ 
194 (placebo: $51.6 \pm 9.6 \mathrm{ml} \cdot \mathrm{kg}^{-1} \cdot \mathrm{min}^{-1}$; caffeine: $51.2 \pm 8.4 \mathrm{ml} \cdot \mathrm{kg}^{-1} \cdot \mathrm{min}^{-1}$; $P=0.860$ ) or $195 W_{\max }$ (placebo: $286 \pm 47 \mathrm{w}$; caffeine: $\left.296 \pm 55 \mathrm{w} ; P=0.667\right)$. Day 21 body mass 196 (placebo: $73.1 \pm 6.8 \mathrm{~kg}$; caffeine: $74.8 \pm 10.2 \mathrm{~kg}$ ), $\dot{\mathrm{V}} \mathrm{O}_{2 \text { peak }}$ (placebo: $51.0 \pm 9.2$ $197 \mathrm{ml} \cdot \mathrm{kg}^{-1} \cdot \mathrm{min}^{-1}$; caffeine: $50.6 \pm 8.3 \mathrm{ml} \cdot \mathrm{kg}^{-1} \cdot \mathrm{min}^{-1}$ ) and $W_{\max }$ (placebo: $282 \pm 43 \mathrm{~W}$; 198 caffeine: $289 \pm 47 \mathrm{~W}$ ) was similar to baseline between both supplementation groups 199 (trial $x$ group interactions, $P>0.646$ ).

200

201

Exercise performance

202 Total external work produced during the testpla trial was similar between the caffeine 203 (344. $9 \pm 80.3 \mathrm{~kJ})$ and placebo (333.1 $\pm 56.4 \mathrm{~kJ})$ group (ES=0.17; $P=0.723 ;$ Fig. 2A). 204 Compared with testpla, total external work produced during the precaf trial increased $20512.0 \pm 7.4 \%$ in the caffeine group $(383.3 \pm 75 \mathrm{~kJ}$ vs. $344.9 \pm 80.3 \mathrm{~kJ}$; ES=0.49; $206 P=0.001)$ and $6.7 \pm 4.2 \%$ in the placebo group $(354.4 \pm 55.2 \mathrm{~kJ}$ vs. $333.1 \pm 56.4 \mathrm{~kJ}$; 207 ES=0.38; $P=0.004$; Fig. 2A). Based on a smallest worthwhile change in performance 208 of $12 \mathrm{~kJ}$, these within-group increases represent an 'almost certainly beneficial' 209 (caffeine group) and 'probably beneficial' (placebo group) effect on performance, 210 respectively (Table. 1$)$.

211 Chronic caffeine supplementation resulted in a $7.3 \pm 6.3 \%$ decrease in total external 212 work produced during the postcaf trial compared with precaf (358 $\pm 89 \mathrm{~kJ}$ vs. $383.3 \pm$ $21375 \mathrm{~kJ}$; ES=-0.31; $P=0.025 ;$ Fig. 2A). This diminished response represents a 'probably 214 harmful' effect on performance (Table. 1). Total external work produced during the 215 postcaf trial and tetspla was not statistically different (358 $\pm 89 \mathrm{~kJ}$ vs. $344.9 \pm 80.3 \mathrm{~kJ}$; $216 E S=0.16 ; P=0.188)$. However, inferences suggest the difference between these trials 217 represents a 'possibly beneficial' effect (Table. 1). Hence, chronic caffeine 
218 supplementation might have not completely eliminated the performance benefit of 219 caffeine (i.e. postcaf vs. testpla; Table. 1).

220 Participants in the placebo group produced $6.1 \pm 2.4 \%$ more external work during the 221 postcaf trial than testpla $(351.8 \pm 49.4 \mathrm{~kJ}$ vs. $333.1 \pm 56.4$; ES=0.33; $P=0.004$; Fig. 222 2A), with this increase representing a 'probably beneficial' effect on performance 223 (Table. 1). Accordingly, there was no difference between the precaf and postcaf trials 224 (354.4 $\pm 55.2 \mathrm{~kJ}$ vs. $351.8 \pm 49.4 \mathrm{~kJ} ; \mathrm{ES}=0.05 ; P>0.05)$.

225 There were no between-group differences during the precaf $(28.7 \pm 74.8 \mathrm{~kJ}$; $226 \mathrm{ES}=0.44 ; P=0.368)$ or postcaf $(6.2 \pm 90.7 \mathrm{~kJ} ; \mathrm{ES}=0.09 ; P=0.858)$ trials (Fig. 2A; 227 Table. 1).

228 The order of the experimental trials was correctly guessed by two participants in 229 each supplementation group. Furthermore, three participants in each 230 supplementation group correctly guessed whether they received the caffeine or 231 placebo treatment during the habituation period. Therefore, blinding can be 232 considered successful as these odds are less than what could occur purely by 233 chance.

235 Blood data

236 Circulating caffeine, cortisol, prolactin and glucose values recorded during exercise 237 are shown in table 2. Acute caffeine supplementation increased serum 238 concentrations during the precaf and postcaf trials, peaking 60 min after ingestion and remaining greater throughout exercise than baseline and testpla (trial $x$ time 240 interaction, $P<0.05)$. There were no changes in serum caffeine concentrations during 
241 testpla, with values remaining close to baseline throughout exercise in both groups.

242 The habituation protocol did not influence caffeine metabolism $(P=0.605)$.

243 Serum cortisol increased progressively throughout exercise $(P<0.05)$, peaking at the

244 end of the performance task in both groups. No influence from trial $(P=0.535)$ or 245 supplementation group $(P=0.628)$ occurred. Similarly, prolactin concentrations 246 increased during exercise $(P<0.05)$, but the rate of increase was similar across trials $247(P=0.498)$ and between groups $(P=0.649)$. The greatest concentrations were at the 248 end of the performance task across all trials in both groups $(P<0.05)$. Neither cortisol $249(P=0.552)$ or prolactin $(P=0.965)$ were influenced by the habituation protocol.

250 Fasting plasma glucose was similar across all three trials in both supplementation 251 groups $(P=0.465)$. During exercise, plasma concentrations increased steadily $252(P<0.05)$, with similar values across trials $(P=0.096)$ and between groups $(P=0.443)$. 253 Compared with baseline, both blood and plasma volumes were reduced during 254 exercise $(P<0.05)$. No influence of trial $(P>0.135)$ or group $(P>0.649)$ occurred.

256 Heart rate, substrate oxidation and RPE

257 Mean heart rate, expired gas and RPE values recorded during exercise are shown in 258 table 3. Exercise caused a progressive increase in heart rate throughout the fixed259 intensity exercise $(P<0.05)$. This increase remained similar across trials $(P=0.169)$ 260 and between supplementation groups $(P=0.984)$. Similarly, heart rate increased 261 during the performance task $(P<0.05)$, but this increase was similar across trials $262(P=0.891)$ and between groups $(P=0.887)$. Within-group differences in mean heart 
263 rate occurred across trials. The greatest values were during the precaf trial in both

264 groups (Table. 3). There were no between-group differences $(P>0.274)$.

265 Rates of carbohydrate oxidation decreased $(P=0.026)$ while rates of fat oxidation 266 increased $(P<0.05)$ during the fixed-intensity exercise. Neither of these were 267 influenced by trial $(P>0.784)$ or group $(P>0.328)$. Furthermore, RER values 268 decreased $(P<0.05)$ while $\dot{V} 02$ increased $(P<0.05)$ during exercise. No influence 269 from trial $(P>0.691)$ or group $(P>0.189)$ occurred.

270 Exercise induced a steady increase in RPE during the fixed intensity exercise $271(P<0.05)$, with similar values across trials $(P=0.265)$ and between groups $(P=0.441)$. 272 Similarly, RPE increased throughout the performance task $(P<0.05)$, but this 273 response was independent of trial $(P=0.174)$ and group $(P>0.05)$.

275 Discussion:

276 This study examined whether four weeks of controlled caffeine intake influenced 277 endurance performance in a group of recreationally active men with low-habitual 278 caffeine intakes. The results of the present study indicate that chronic 279 supplementation with a titrated low dose of caffeine developed tolerance to the 280 ergogenic effect a subsequent acute caffeine dose. While these results contrast with 281 previous studies that have examined effects of sub-chronic caffeine supplementation 282 (Irwin et al., 2011), this is the first study to examine effects of a prolonged period of 283 controlled caffeine intake typical of the general population (Fitt et al., 2013). This 284 suggests that supplementation protocols in previous studies (Irwin et al., 2011) were 285 too short to influence mechanisms that develop tolerance. 
286 Previous research demonstrated caffeine prolonged time-to-exhaustion because it 287 enhanced fat oxidation late in exercise with a subsequent sparring of muscle 288 glycogen (Costill, Dalsky, \& Fink, 1978). The results of the present study are contrary 289 to this as substrate oxidation was not influenced either by acute or chronic caffeine 290 supplementation. Alternatively, chronic caffeine intake could influence caffeine 291 metabolism (Svenningsson et al., 1999). This might lead to an increase in the 292 concentrations of paraxanthine and theophylline, caffeine's primary metabolites 293 (Svenningsson et al., 1999). As these possess a greater affinity for adenosine 294 receptors than caffeine (Fredholm et al., 1999), this could result in enhanced 295 development of tolerance. However, caffeine concentrations were similar between 296 the precaf and postcaf trials in the caffeine group (Table. 2), suggesting the 297 habituation protocol failed to influence caffeine metabolism. Although paraxanthine 298 and theophylline concentrations were not measured, these methylxanthines do not penetrate the blood-brain-barrier with the same efficacy as caffeine (Svenningsson 300 et al., 1999). Therefore, any subtle change in the peripheral concentrations of these 301 metabolites attributable to the chronic supplementation protocol is unlikely to explain 302 the development of tolerance.

303 Serum cortisol and prolactin were assessed as these are indirect indicators of central 304 noradrenergic (Tsigos \& Chrousos, 2002) and dopaminergic (Ben-Jonathan \& 305 Hnasko, 2001) activity, respectively. Chronic caffeine supplementation did not 306 influence the circulating concentrations of these hormones (Table. 2), suggesting 307 that neurotransmitter release along these neural pathways does not explain the 308 development of tolerance. Direct analysis of neurotransmitter release with 309 microdialysis (Acquas, Tanda, \& Di Chiara, 2002; De Luca, Bassareo, Bauer, \& Di 310 Chiara, 2007) and brain imaging techniques (Volkow et al., 2015) also support this 
311 hypothesis. Although high acute caffeine doses increase striatal dopamine release

312 (i.e. $30 \mathrm{mg} \cdot \mathrm{kg}^{-1}$; Solinas et al., 2002), lower doses (i.e. $0.25-5 \mathrm{mg} \cdot \mathrm{kg}^{-1}$ ), typically

313 consumed by the general population (Fitt et al., 2013), have not influenced dopamine

314 release both in rat (Acquas et al., 2002; De Luca et al., 2007) and human (Volkow et

315 al., 2015) striatum. Therefore, an alternative mechanism is likely responsible.

316 Chronic caffeine supplementation has been associated with changes in $A_{2 A}$ 317 expression across several brain regions (Svenningsson et al., 1999). However, a 318 cross-tolerance to the $A_{1}$ receptor probably plays a more important role in mediating 319 the development of tolerance (Karcz-Kubicha et al., 2003). This could involve a 320 functional change in the striatal $A_{1} / A_{2 A}$ heteromer (Ciruela et al., 2006), while others 321 have reported changes in $A_{1}$ receptor expression throughout the brain after chronic 322 caffeine supplementation (Johansson et al., 1993). A recent positron emission topography study demonstrated that almost half of in vivo cerebral $A_{1}$ receptors were 324 occupied by caffeine when participants received an intravenous dose of $4.3 \mathrm{mg} \cdot \mathrm{kg}^{-1}$, 325 which corresponded to a plasma concentration of $\sim 8 \mu \mathrm{g} \cdot \mathrm{mL}^{-1}$ (Elmenhorst, Meyer, 326 Matusch, Winz, \& Bauer, 2012). Participants in the present study were habituated to 327 daily doses of $3 \mathrm{mg} \cdot \mathrm{kg}^{-1}$ from days 8 to 28 , resulting in serum concentrations of 328 approximately $3.5 \mu \mathrm{g} \cdot \mathrm{mL}^{-1}$ (Table. 2). Based on these observations, it could be that 329 the $3 \mathrm{mg} \cdot \mathrm{kg}^{-1}$ caffeine dose administered in the present study resulted in the 330 occupation of approximately a quarter of cerebral $A_{1}$ receptors. This suggests 331 supplementation with larger daily caffeine doses (i.e. 6-9 $\mathrm{mg} \cdot \mathrm{kg}^{-1}$ ), which will 332 ultimately occupy more $A_{1}$ receptors, results in accelerated and/or total development of tolerance.

334 The influence of caffeine habituation in participants is often overlooked in many studies, despite evidence which demonstrates that this influences effects after acute 
336 supplementation (Bell \& McLellan, 2002). To minimise this confounder, all 337 participants in the present study were low caffeine consumers before participation. 338 Differences in habitual caffeine consumption are associated with single nucleotide 339 polymorphisms in the ADORA2A gene encoding for the $A_{2 A}$ receptor (Cornelis, El340 Sohemy, \& Campos, 2007). These findings demonstrated individuals with the 341 homozygous recessive (TT) genotype consumed less caffeine than their 342 homozygous dominant (CC) counterparts (Cornelis et al., 2007). Recently, TT 343 carriers performed better during a short performance task (10 min) than CC carriers 344 when supplemented with an acute $5 \mathrm{mg} \cdot \mathrm{kg}^{-1}$ caffeine dose (Loy, O'Connor, 345 Lindheimer, \& Covert, 2015). Perhaps this could explain the small between-group 346 difference in total external work produced during the precaf trial $(28.7 \pm 74.8 \mathrm{~kJ}$; 347 ES=0.44), with more TT carriers present in the caffeine group. However, genotype 348 determination was not undertaken in the present study, which limits the extent to 349 which this relationship can be inferred.

350 Well-trained individuals produce more reliable performance data during cycle-based 351 time-trials than their recreationally active counterparts (Zavorsky et al., 2007). 352 However, recreationally active individuals produced a CV of $1.7 \%$ (Zavorsky et al., 353 2007) and $0.7 \%$ (Fleming and James, 2014) during cycle and running-based time354 trials, respectively. Furthermore, similar performance tests to that in the present 355 study had a CV of approximately 3\% (Jeukendrup et al., 1996). This variability is less than the percentage increase in performance during the precaf trials (caffeine: $12.0 \pm$ 7.4\%; placebo: $6.7 \pm 4.2 \%$ ) and the percentage decrease in performance during the 358 postcaf trial compared with precaf in the caffeine group $(-7.3 \pm 6.3 \%)$. Therefore, 359 neither the participant group nor the performance test used in the present study 360 adversely influenced the validity of the performance data. 
361 Ideally, the study design would have incorporated a post-supplementation placebo

362 trial, hence providing a direct comparison with the postcaf trial after the chronic 363 supplementation protocol. It was deemed difficult to implement as timing both trials 364 to occur at the end of the supplementation period was not possible. For example, 365 two randomised trials, undertaken seven days apart, means the supplementation 366 period before the postcaf trial would be twenty-eight days for half the participants 367 and thirty-five days for the remaining participants. Importantly, peak power output 368 and maximal oxygen uptake were similar between the two $\dot{\mathrm{V}} \mathrm{O}_{2 \text { peak }}$ tests. Furthermore, heart rate and oxygen uptake during the fixed-intensity exercise was similar during 370 all three trials. This suggests participants maintained similar fitness throughout the 371 study period and exercise intensity was matched before the performance task during each of the experimental trials. Hence, any influence on performance during the 373 postcaf trial in either supplementation group is likely due to participants receiving 374 caffeine or placebo during the chronic supplementation period.

375 In conclusion, the present findings demonstrate that chronic ingestion of a titrated 376 low dose of caffeine results in the development of tolerance in a group of healthy, 377 recreationally active males with low-habitual caffeine intakes. This occurred despite 378 no changes before and after supplementation in circulating caffeine, hormonal 379 concentrations or substrate oxidation. The influence of chronic caffeine intake should 380 be examined in well-trained individuals with low-habitual caffeine intakes. In addition, 381 futures studies should identify when the tolerance to caffeine occurs and examine 382 whether supplementation with larger daily doses (i.e. $6-9 \mathrm{mg} \cdot \mathrm{kg}^{-1}$ ) influences the 383 rate and extent of the development of tolerance. 
385 Acknowledgements: The study did not receive any external funding.

386

387

388

389

390

391

392

393

394

395

396

397

398

399

400

401

402

403 
404 References

405 Acquas, E., Tanda, G., \& Di Chiara, G. (2002). Differential effects of caffeine on 406 dopamine and acetylcholine transmission in brain areas of drug-naive and caffeine407 pretreated rats. Neuropsychopharmacology, 27, 182-193.

408 Addicot, M. A., Yang, L. L, Peiffer, A. M., \& Laurienti, P. J. (2008). Methodological 409 considerations for the quantification of self-reported caffeine use. 410 Psychopharmacology, 203, 571-578.

411 Bangsbo, J., Jacobsen, K., Nordberg, N., Christensen, N. J., \& Graham, T. E. (1992). 412 Acute and habitual caffeine ingestion and metabolic responses to steady-state 413 exercise. Journal of Applied Physiology, 72, 1297-1303.

414 Bell, D. G., \& McLellan, T. M. (2002). Exercise endurance 1, 3, and 6 h after caffeine 415 ingestion in caffeine users and nonusers. Journal of Applied Physiology, 93, 12274161234.

417 Ben-Jonathan, N., \& Hnasko, R. (2001). Dopamine as a prolactin (PRL) inhibitor. 418 Endocrinology Reviews, 22, 724-763.

419 Berglund, B., \& Hemmingsson, P. (1982). Effects of caffeine ingestion on exercise 420 performance at low and high altitudes in cross-country skiers. International Journal of 421 Sports Medicine, 3, 234-236.

422 Borg, G. A. (1982). Psychophysical bases of perceived exertion. Medicine and 423 Science in Sports and Exercise, 14, 377-381. 
424 Burke, L. M. (2008). Caffeine and sports performance. Applied Physiology, Nutrition, 425 and Metabolism, 33, 1319-1334.

426 Ciruela, F., Casado, V., Rodrigues R. J., Luján, R., Burgueño, J., Canals, 427 M., ...Franco, R. (2006). Presynaptic control of striatal glutamatergic 428 neurotransmission by adenosine A1-A2A receptor heteromers. Journal of 429 Neuroscience, 26, 2080-2087.

430 Cohen, J. (1992). A power primer. Psychological Bulletin, 112, 115-119

431 Cornelis, M. C., El-Sohemy, A., \& Campos, H. (2007). Genetic polymorphism of the 432 adenosine A2A receptor is associated with habitual caffeine consumption. American 433 Journal of Clinical Nutrition, 86, 240-244.

434 Costill, D. L., Dalsky, G. P., \& Fink, W. J. (1978). Effects of caffeine ingestion on 435 metabolism and exercise performance. Medicine and Science in Sports and Exercise, $43610,155-158$.

437 Cox, G. R., Desbrow, B., Montgomery, P. G., Anderson, M. E., Bruce, C. R., 438 Macrides, T. A., ...Burke, L. M. (2002). Effect of different protocols of caffeine intake 439 on metabolism and endurance performance. Journal of Applied Physiology, 93, 990440999.

441 De Luca, M. A., Bassareo, V., Bauer, A., \& Di Chiara, G. (2007). Caffeine and 442 accumbens shell dopamine. Journal of Neurochemistry, 103, 157-163. 
443 Desbrow, B., Biddulph, C., Delvin, B., Grant, G. D., Anoopkumar-Dukie, S., \& 444 Leveritt, M. D. (2012). The effects of different doses of caffeine on endurance cycling 445 time trial performance. Journal of Sports Science, 30, 115-120.

446 Desbrow, B., \& Leveritt, M. D. (2006). Awareness and use of caffeine by athletes 447 competing at the 2005 Ironman Triathlon World Championships. International 448 Journal of Sport Nutrition and Exercise Metabolism, 16, 545-558.

449 Dill, D. B., \& Costill, D. L. (1974). Calculation of percentage changes in volumes of 450 blood, plasma, and red cells in dehydration. Journal of Applied Physiology, 37, 247451248.

452 El Yacoubi, M., Ledent, C., Menard, J. F., Parmentier, M., Costentin, J., \& Vaugeois, 453 J. M. (2000). The stimulant effects of caffeine on locomotor behaviour in mice are 454 mediated through its blockade of adenosine $A(2 A)$ receptors. British Journal of 455 Pharmacology, 129, 1465-1473.

456 Elmenhorst, D., Meyer, P. T., Matusch, A., Winz, O. H., \& Bauer, A. (2012). Caffeine 457 occupancy of human cerebral A1 adenosine receptors: in vivo quantification with 458 18F-CPFPX and PET. Journal of Nuclear Medicine, 53, 1723-1729.

459 Fitt, E., Pell, D., \& Cole, D. (2013). Assessing caffeine intake in the United Kingdom 460 diet. Food Chemistry, 140, 421-426. 
461 Fleming, J., \& James, L. J. (2014). Repeated familiarisation with hypohydration

462 attenuates the performance decrement caused by hypohydration during treadmill 463 running. Applied Physiology, Nutrition, and Metabolism, 39, 124-129. doi: 10.1139

464 Fredholm, B. B., Battig, K., Holmen, J., Nehlig, A., \& Zvartau, E. E. (1999). Actions of 465 caffeine in the brain with special reference to factors that contribute to its widespread 466 use. Pharmacological Reviews, 51, 83-133.

467 Hodgson, A. B., Randell, R. K., \& Jeukendrup, A. E. (2013). The metabolic and 468 performance effects of caffeine compared to coffee during endurance exercise. 469 PLoS One, 8, e59561. doi: 10.1371

470 Holland, D. T., Godfredsen, K. A., Page, T., \& Connor, J. D. (1998). Simple high471 performance liquid chromatography method for the simultaneous determination of 472 serum caffeine and paraxanthine following rapid sample preparation. Journal of 473 Chromatography B: Biomedical Sciences and Applications, 707, 105-110.

474 Hopkins, W. G. (2000). A new view of statistics. Internet society for sport science. 475 Retrieved 24 August 2016 from http:www.sportsci.org

476 Irwin, C., Desbrow, B., Ellis, A., O’Keeffe, B., Grant, G., \& Leveritt, M. (2011). 477 Caffeine withdrawal and high-intensity endurance cycling performance. Journal of 478 Sports Sciences, 29, 509-515. 
479 Jenkins, N. T., Trilk, J. L., Singhal, A., O'Connor, P. J., \& Cureton, K. J. (2008). 480 Ergogenic effects of low doses of caffeine on cycling performance. International 481 Journal of Sport Nutrition and Exercise Metabolism, 18, 328-342.

482 Jeukendrup, A., Saris, W. H., Brouns, F., \& Kester, A. D. (1996). A new validated 483 endurance performance test. Medicine and Science in Sports and Exercise, 28, 266$484 \quad 270$

485 Johansson, B., Ahlberg, S., van der Ploeg, I., Brené, S., Lindefors, N., Persson, H., \& 486 Fredholm, B. B. (1993). Effect of long term caffeine treatment on A1 and A2A 487 adenosine receptor binding and on mRNA levels in rat brain. Naunyn488 Schmiedeberg's Archives of Pharmacology, 347, 407-414.

489 Karcz-Kubicha, M., Antoniou, K., Terasmaa, A., Quarta, D., Solinas, M., Justinova, 490 Z., ...Ferré, S. (2003). Involvement of adenosine A1 and A2A receptors in the motor 491 effects of caffeine after its acute and chronic administration. 492 Neuropsychopharmacology, 28, 1281-1291.

493 Loy, B. D., O'Connor, P. J., Lindheimer, J. B., \& Covert, S. F. (2015). Caffeine is 494 ergogenic for adenosine A2A receptor gene (ADORA2A) T Allele homozygotes: a 495 pilot study. Journal of Caffeine Research, 5, 73-81. doi: 10.1089.

496 Peronnet, F., \& Massicotte, D. (1991). Table of nonprotein respiratory quotient: an 497 update. Canadian Journal of Sport Sciences, 16, 23-29. 
498 Quarta, D., Ferré, S., Solinas, M., You, Z. B., Hockemeyer, J., Popoli, P., \& Goldberg, 499 S. R. (2004). Opposite modulatory roles for adenosine A1 and A2A receptors on 500 glutamate and dopamine release in the shell of the nucleus accumbens. Effects of 501 chronic caffeine exposure. Journal of Neurochemistry, 88, 1151-1158.

502 Roti, M. W., Casa, D. J., Pumerantz, A. C., Watson, G., Judelson, D. A., Dias 503 JC., ...Armstrong, L. E. (2006). Thermoregulatory responses to exercise in the heat: 504 chronic caffeine intake has no effect. Aviation, Space, and Environmental Medicine, $505 \quad 77,124-129$.

506 Snyder, S. H., Katims, J. J., Annau, Z., Bruns, R. F., \& Daly, J. W. (1981). Adenosine 507 receptors and behavioural actions of methylxanthines. Proceedings of the National 508 Academy of Sciences, 78, 3260-3264.

509 Solinas, M., Ferré, S., You, Z. B., Karcz-Kubicha, M., Popoli, P., \& Goldberg, S. R. 510 (2002). Caffeine induces dopamine and glutamate release in the shell of the nucleus 511 accumbens. Journal of Neuroscience, 22, 6321-6324.

512 Svenningsson, P., Nomikos, G. G., \& Fredholm, B. B. (1999). The stimulatory action 513 and the development of tolerance to caffeine is associated with alterations in gene 514 expression in specific brain regions. Journal of Neuroscience, 19, 4011-4022.

515 Tepper, J. M., Wilson, C. J., \& Koós, T. (2008). Feedforward and feedback inhibition 516 in neostriatal GABAergic spiny neurons. Brain Research Reviews, 58, 272-281. 
517 Tsigos, C., \& Chrousos, G. P. (2002). Hypothalamic-pituitary-adrenal axis, 518 neuroendocrine factors and stress. Journal of Psychosomatic Research, 53, 865-871.

519 Volkow, N. D., Wang, G. J., Logan, J., Alexoff, D., Fowler, J. S., Thanos, P. 520 K., ...Tomasi, D. (2015). Caffeine increases striatal dopamine $D_{2} / D_{3}$ receptor 521 availability in the human brain. Translational Psychiatry, 5, e549. doi: 10.1038

522 Zavorsky, G. S., Murias, J. M., Gow, J., Kim, D. J., Poulin-Harnois, C., Kubow, S., \& 523 Lands, L. C. (2007). Laboratory $20-\mathrm{km}$ cycle time trial reproducibility. International 524 Journal of Sports Medicine, 28, 743-748. 
Table 1: Differences in total external work produced $(\mathrm{kJ})$ during the experimental trials within and between supplementation groups

\begin{tabular}{|c|c|c|c|}
\hline Treatment comparison & $\begin{array}{l}\text { Mean } \pm \text { SD difference and } \\
95 \% \text { confidence interval }(\mathrm{kJ})\end{array}$ & ES & $\begin{array}{c}\text { Qualitative outcome } \\
\text { (beneficial/trivial/harmful) }\end{array}$ \\
\hline CAF & & & Almost certainly beneficial \\
\hline \multirow{2}{*}{ Precaf-testpla } & $38.4 \pm 19.9(18.4$ to 58.4$)$ & 0.49 & $(100 / 0 / 0)$ \\
\hline & & & Possibly beneficial \\
\hline \multirow[t]{2}{*}{ Postcaf-testpla } & $13.1 \pm 18.2(-5.2$ to 31.3$)$ & 0.16 & $(55 / 44 / 1)$ \\
\hline & & & Probably harmful \\
\hline Postcaf-precaf & $-25.3 \pm 21.9(-47.3$ to -3.4$)$ & -0.31 & $(0 / 9 / 91)$ \\
\hline PLA & & & Probably beneficial \\
\hline \multirow[t]{2}{*}{ Precaf-testpla } & $21.4 \pm 13.1$ (8.3 to 34.7$)$ & 0.38 & $(94 / 6 / 0)$ \\
\hline & & & Probably beneficial \\
\hline \multirow[t]{2}{*}{ Postcaf-testpla } & $18.7 \pm 11.9(6.8$ to 30.6$)$ & 0.33 & $(91 / 9 / 0)$ \\
\hline & & & Unclear \\
\hline Postcaf-precaf & $-2.8 \pm 9.8(-12.7$ to 7.1$)$ & -0.05 & $(50 / 0 / 50)$ \\
\hline Testpla & & & Unclear \\
\hline CAF-PLA & $11.8 \pm 89.7(-58.3$ to 81.9$)$ & 0.17 & $(50 / 26 / 24)$ \\
\hline Precaf & & & Unclear \\
\hline CAF-PLA & $28.7 \pm 74.8(-37.7$ to 95.2$)$ & 0.44 & $(70 / 19 / 11)$ \\
\hline Postcaf & & & Unclear \\
\hline CAF-PLA & $6.2 \pm 90.7(-68.1$ to 80.5$)$ & 0.09 & $(43 / 26 / 30)$ \\
\hline
\end{tabular}

PLA, Placebo group; CAF, Caffeine group; ES, Cohen's $d$ effect size. Qualitative outcome numbers indicate the percentage chance the true value is beneficial, trivial or harmful based on a $12 \mathrm{~kJ}$ difference in external work produced during the performance task. An effect was deemed unclear when the percentage chances of benefit and harm were $>5 \%$. 
Table 2: Circulating caffeine, cortisol, prolactin and glucose concentrations during the experimental trials.

\begin{tabular}{|c|c|c|c|c|c|c|c|c|}
\hline \multirow[b]{2}{*}{ Variable } & \multicolumn{4}{|c|}{ PLA } & \multicolumn{4}{|c|}{ CAF } \\
\hline & -60 & 0 & 60 & 90 & -60 & 0 & 60 & 90 \\
\hline \multicolumn{9}{|c|}{ Caffeine $\left(\mu \mathrm{g} \cdot \mathrm{mL}^{-1}\right)$} \\
\hline Testpla & $0.06 \pm 0.07$ & $0.06 \pm 0.07$ & $0.06 \pm 0.07$ & $0.07 \pm 0.06$ & $0.13 \pm 0.07$ & $0.08 \pm 0.10$ & $0.10 \pm 0.08$ & $0.05 \pm 0.08$ \\
\hline Precaf & $0.09 \pm 0.07$ & $3.54 \pm 0.59^{\star \#}$ & $3.17 \pm 0.44^{\star^{\#}}$ & $2.97 \pm 0.23^{\star^{\#}}$ & $0.28 \pm 0.29$ & $3.48 \pm 0.57^{\star \#}$ & $3.40 \pm 0.53^{\star^{\#}}$ & $3.03 \pm 0.56^{\star^{\#}}$ \\
\hline Postcaf & $0.10 \pm 0.09$ & $3.54 \pm 0.65^{\star^{\#}}$ & $3.22 \pm 0.44^{\star^{\#}}$ & $2.97 \pm 0.55^{\star^{\#}}$ & $0.49 \pm 0.37$ & $3.69 \pm 0.60^{\star \#}$ & $3.26 \pm 0.53^{\star \#}$ & $3.09 \pm 0.66^{\star^{\#}}$ \\
\hline \multicolumn{9}{|c|}{ Cortisol $\left(\mathrm{ng} \cdot \mathrm{mL}^{-1}\right)$} \\
\hline Testpla & $131.55 \pm 37.22$ & $125.29 \pm 59.77$ & $153.22 \pm 75.59$ & $211.17 \pm 90.96$ & $115.47 \pm 14.78$ & $85.30 \pm 33.50$ & $163.73 \pm 20.75^{\star}$ & $236.10 \pm 51.18^{*}$ \\
\hline Precaf & $142.13 \pm 26.85$ & $118.00 \pm 50.96$ & $177.90 \pm 86.66$ & $227.32 \pm 90.89$ & $136.25 \pm 34.27$ & $104.55 \pm 26.11$ & $159.76 \pm 46.14$ & $225.63 \pm 48.25$ \\
\hline Postcaf & $146.42 \pm 33.79$ & $122.48 \pm 36.89$ & $185.70 \pm 63.54$ & $249.50 \pm 71.88$ & $121.87 \pm 42.89$ & $80.30 \pm 38.35$ & $168.10 \pm 42.36$ & $234.73 \pm 38.28^{*}$ \\
\hline \multicolumn{9}{|c|}{ Prolactin $\left(\mathrm{ng} \cdot \mathrm{mL}^{-1}\right)$} \\
\hline Testpla & $8.13 \pm 2.68$ & $7.80 \pm 3.16$ & $10.01 \pm 2.80$ & $19.65 \pm 4.43^{*}$ & $7.83 \pm 3.86$ & $7.84 \pm 3.02$ & $9.99 \pm 2.79$ & $20.53 \pm 4.99^{*}$ \\
\hline Precaf & $7.91 \pm 1.78$ & $7.43 \pm 1.46$ & $10.39 \pm 2.13$ & $19.42 \pm 3.18^{*}$ & $7.89 \pm 3.65$ & $7.57 \pm 3.31$ & $10.23 \pm 2.10$ & $20.03 \pm 5.22^{\star}$ \\
\hline Postcaf & $7.59 \pm 2.50$ & $8.78 \pm 3.27$ & $10.37 \pm 1.16^{*}$ & $19.25 \pm 3.69^{*}$ & $8.33 \pm 3.31$ & $7.94 \pm 3.66$ & $9.79 \pm 3.06$ & $19.68 \pm 5.06^{*}$ \\
\hline \multicolumn{9}{|c|}{ Glucose $\left(\mathrm{mmol} \cdot \mathrm{L}^{-1}\right)$} \\
\hline Testpla & $4.17 \pm 0.27$ & $4.18 \pm 0.38$ & $4.45 \pm 0.51$ & $4.71 \pm 0.82$ & $4.26 \pm 0.28$ & $4.21 \pm 0.35$ & $4.50 \pm 0.39$ & $5.03 \pm 0.57$ \\
\hline Precaf & $4.10 \pm 0.30$ & $4.10 \pm 0.35$ & $4.52 \pm 0.51$ & $4.99 \pm 1.03$ & $4.19 \pm 0.42$ & $4.21 \pm 0.35$ & $4.49 \pm 0.32$ & $5.35 \pm 0.77$ \\
\hline Postcaf & $4.18 \pm 0.22$ & $4.22 \pm 0.17$ & $4.70 \pm 0.48$ & $5.06 \pm 0.75$ & $4.41 \pm 0.39$ & $4.25 \pm 0.25$ & $4.57 \pm 0.37$ & $5.32 \pm 0.76$ \\
\hline
\end{tabular}

Values are mean \pm SD. PLA, Placebo group; CAF, Caffeine group. *denotes a within-trial significant difference $(P<0.05)$ compared with -60 . ${ }^{\#}$ denotes a

significant difference $(P<0.05)$ compared with the corresponding time point in the testpla trial. There were no significant trial $x$ group $(P>0.552)$, time $x$ group $(P>0.443)$ or trial $x$ time $\times$ group $(P>0.512)$ interactions for any variable. 
Table 3: Mean heart rate, RPE and substrate oxidation during the experimental trials.

\begin{tabular}{|c|c|c|c|c|}
\hline Variable & testpla & precaf & postcaf & $P$ \\
\hline \multicolumn{5}{|c|}{ Heart rate (beats $\cdot \mathrm{min}^{-1}$ ), fixed } \\
\hline PLA & $146 \pm 7$ & $145 \pm 7$ & $145 \pm 8$ & \\
\hline CAF & $145 \pm 6$ & $144 \pm 7$ & $146 \pm 7$ & 0.312 \\
\hline \multicolumn{5}{|c|}{ Heart rate (beats $\cdot \mathrm{min}^{-1}$ ), PT } \\
\hline PLA & $167 \pm 13$ & $172 \pm 12^{*}$ & $172 \pm 12^{*}$ & \\
\hline CAF & $169 \pm 9$ & $177 \pm 5^{*}$ & $171 \pm 9 \dagger$ & 0.034 \\
\hline \multicolumn{5}{|c|}{ RPE, fixed } \\
\hline PLA & $12.7 \pm 0.3$ & $12.1 \pm 0.8$ & $11.9 \pm 1.2$ & \\
\hline CAF & $12.9 \pm 1.2$ & $12.7 \pm 1.1$ & $13.0 \pm 1.1$ & 0.219 \\
\hline \multicolumn{5}{|l|}{ RPE, PT } \\
\hline PLA & $15.8 \pm 0.8$ & $15.8 \pm 1.0$ & $15.6 \pm 1.3$ & \\
\hline CAF & $16.4 \pm 1.0$ & $16.8 \pm 1.3$ & $16.6 \pm 0.9$ & 0.478 \\
\hline \multicolumn{5}{|c|}{$\mathrm{CHO} O x\left(\mathrm{~g} \cdot \mathrm{min}^{-1}\right)$} \\
\hline PLA & $2.02 \pm 0.09$ & $2.07 \pm 0.05$ & $1.97 \pm 0.10$ & \\
\hline CAF & $2.25 \pm 0.09$ & $2.37 \pm 0.09$ & $2.16 \pm 0.21$ & 0.871 \\
\hline \multicolumn{5}{|c|}{ Fat $O x\left(g \cdot \mathrm{min}^{-1}\right)$} \\
\hline PLA & $0.40 \pm 0.06$ & $0.38 \pm 0.04$ & $0.42 \pm 0.05$ & \\
\hline CAF & $0.32 \pm 0.05$ & $0.29 \pm 0.06$ & $0.37 \pm 0.09$ & 0.794 \\
\hline \multicolumn{5}{|l|}{ RER } \\
\hline PLA & $0.90 \pm 0.01$ & $0.90 \pm 0.01$ & $0.89 \pm 0.01$ & \\
\hline CAF & $0.92 \pm 0.01$ & $0.92 \pm 0.01$ & $0.91 \pm 0.02$ & 0.882 \\
\hline \multicolumn{5}{|c|}{ VंO2 $\left(L \cdot \min ^{-1}\right)$} \\
\hline PLA & $2.32 \pm 0.06$ & $2.30 \pm 0.06$ & $2.30 \pm 0.09$ & \\
\hline CAF & $2.31 \pm 0.04$ & $2.34 \pm 0.06$ & $2.34 \pm 0.04$ & 0.472 \\
\hline
\end{tabular}

Values are mean \pm SD. PLA, Placebo group; CAF, Caffeine group; CHO Ox, carbohydrate oxidation; Fat Ox, fat oxidation; RER, respiratory exchange ratio; $\mathrm{VO} 2, \mathrm{O}_{2}$ consumption; RPE, rating of perceived exertion. Fixed, values recorded during the fixed-intensity exercise; PT, values recorded during the performance task. $P$ values are derived from trial $x$ group interactions. *denotes a within-group significant difference $(P<0.05)$ compared with testpla. †denotes a within-group comparison $(P=0.061)$ to precaf. 
Figure Captions

Fig. 1: Schematic of the study design

Fig. 2: Total external work produced $(\mathrm{kJ})$ during the experimental trials $(A)$ and individual responses by participants in the placebo (B) and caffeine (C) supplementation group, respectively. A: Trial x group interaction $(P=0.017)$ * and \# denote a within-group significant difference $(P<0.05)$ compared with testpla and precaf, respectively. 


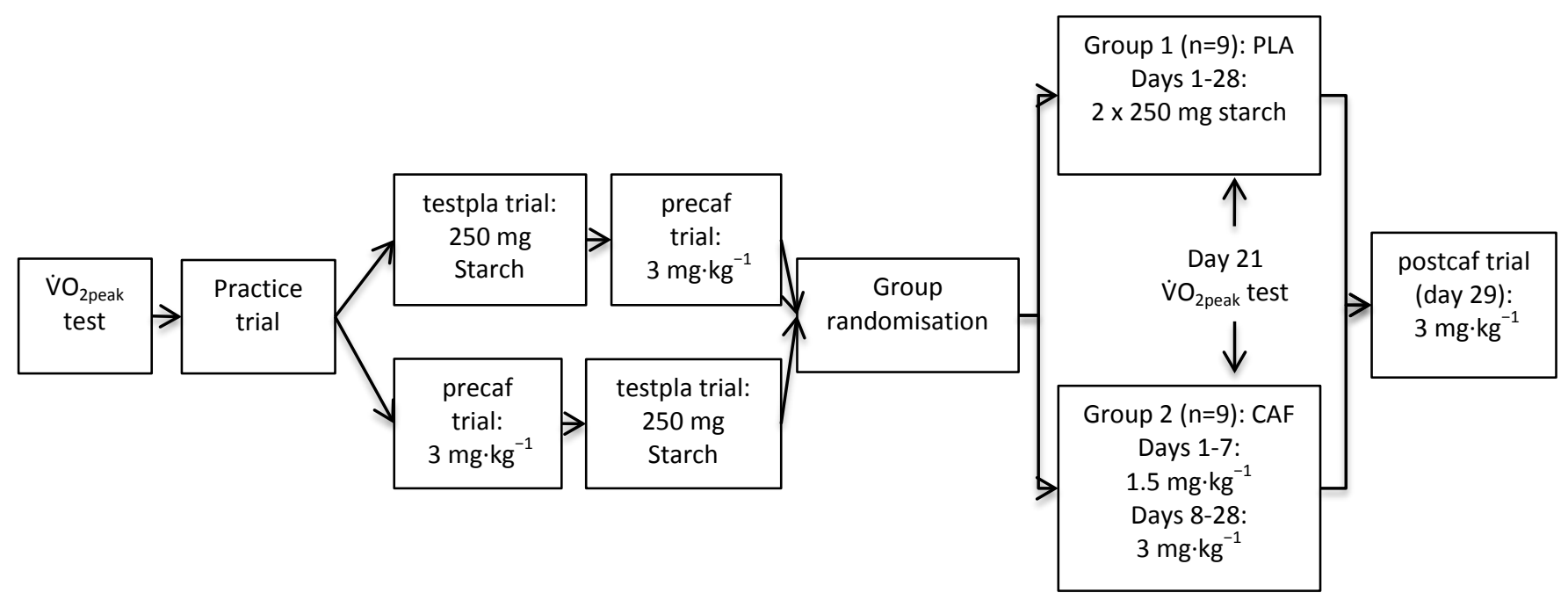




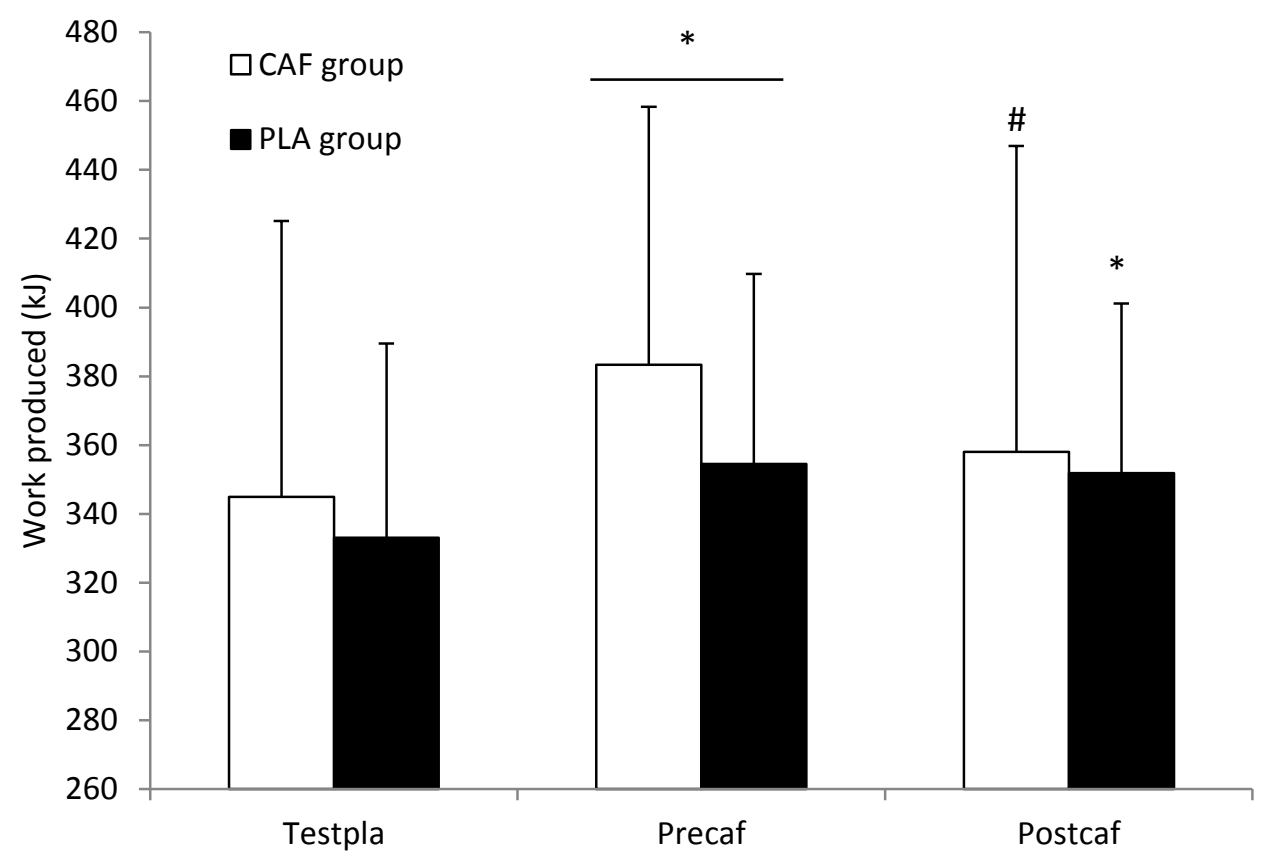

